\title{
Erratum de : La gouttière chirurgicale, place dans la chirurgie orthognathique et perspectives
}

\section{J.T. Bachelet ${ }^{1}$, J. Y. Cliet ${ }^{2}$, J. Chauvel-Picard ${ }^{2}$ et P. Bouletreau ${ }^{3}$}

1 Chirurgien maxillo-facial, Chef de clinique des Universités-assistant des hôpitaux - service de chirurgie maxillo-faciale de l'hôpital de la croix rousse et de l'hôpital femme-mère-enfant

2 Service de stomatologie et chirurgie maxillo-faciale - Centre hospitalier Lyon Sud

3 Chirurgien maxillo-facial, Professeur des Universités et Chef du service adjoint de stomatologie et chirurgie maxillo-faciale du centre hospitalier Lyon Sud

Rev Orthop Dento Faciale, 50 (1) 71 - 76,

http://dx.doi.org/10.1051/odf/2015050

La figure 4 de cet article a été reproduite et publiée sans sa légende. L'éditeur a omis sa publication et s'en excuse auprès des lecteurs et des auteurs. Ci-après la figure 4 avec sa légende :

Figure 4 : Réalisation de moulage numérique (systéme lythos ormco) Construction virtuelle de la gouttière chirurgicale (Dolphin imaging) Impression 3D des gouttières chirurgicales (AAO).

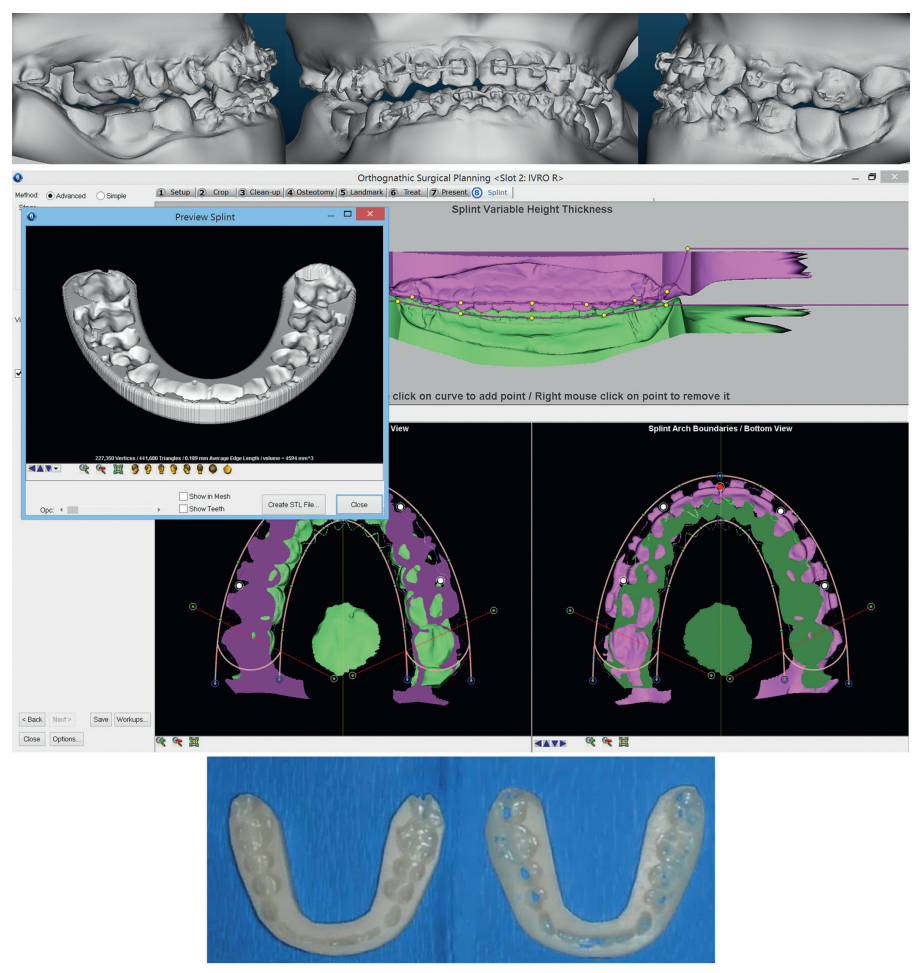

Adresse de correspondance : Jean Thomas Bachelet - Service de stomatologie et chirurgie maxillo-faciale Centre hospitalier Lyon-Sud - 165, Chemin du Grand Revoyet - 69310 Pierre-Bénite jt125_2@hotmail.com 